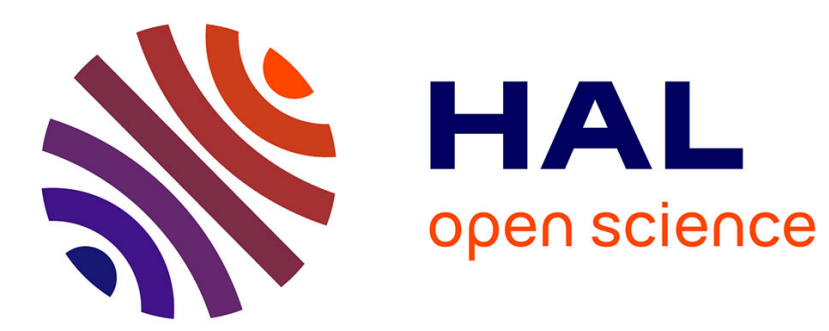

\title{
Commitment: the term and the notions
}

Philippe de Brabanter, Patrick Dendale

\section{To cite this version:}

Philippe de Brabanter, Patrick Dendale. Commitment: the term and the notions. Philippe De

Brabanter \& Patrick Dendale. Commitment, John Benjamins, pp.1-14, 2008. ijn_00344897

\section{HAL Id: ijn_00344897 \\ https://hal.science/ijn_00344897}

Submitted on 6 Dec 2008

HAL is a multi-disciplinary open access archive for the deposit and dissemination of scientific research documents, whether they are published or not. The documents may come from teaching and research institutions in France or abroad, or from public or private research centers.
L'archive ouverte pluridisciplinaire HAL, est destinée au dépôt et à la diffusion de documents scientifiques de niveau recherche, publiés ou non, émanant des établissements d'enseignement et de recherche français ou étrangers, des laboratoires publics ou privés. 


\title{
COMMITMENT: THE TERM AND THE NOTIONS
}

\author{
Philippe De Brabanter and Patrick Dendale \\ Institut Jean Nicod \& Université Paris 4-Sorbonne; University of Antwerp
}

This volume brings together thoroughly reworked versions of a selection of papers presented at the conference The Notion of Commitment in Linguistics, held at the University of Antwerp in January 2007. It is the companion volume to a collection of essays in French to be published in Langue Française and devoted to La notion de prise en charge. Commitment is a close counterpart to prise en charge, and two contributors, Celle and Lansari, use it essentially as a translation of the French term. However, commitment and its verbal cognates (to commit NP to and to be committed to) do not cover the exact same range of meanings as prise en charge. For a thorough assessment of the French term, we refer readers to the introduction to the Langue Française volume. In the present article, we focus entirely on commitment.

The term is widely used in at least three major areas of linguistic enquiry: ${ }^{1}$ studies on illocutionary acts, studies on modality and evidentiality, and the formal modelling of dialogue/argumentation. In spite of its frequent use, the notion has rarely been theorised and has never been the subject of a monograph or a specialised reader. In keeping with this is the fact that none of the many dictionaries and encyclopaedias of linguistics or philosophy that we have consulted devotes a separate entry to it.

Section 1 of this introduction briefly reviews what commitment means in the three fields just mentioned. Now and then, with respect to a particular issue, pointers are given to which articles in this collection have something to say about the issue. In section 2, we take a lexical and syntactic look at the ways in which the contributors to the present volume use the term. In section 3, we outline each of the contributions, with a focus on the role that commitment plays in them.

\section{Background}

\subsection{Speech-act theory}

In speech-act theory, the term has been used, informally at least, since the very first days of the discipline. In his William James lectures of 1955, Austin talks of speech acts "committing [one] to certain future conduct" (Austin 1975: 89). In this context, the term is used first and foremost in connection with 
'commissives' (acts of promising, pledging oneself, guaranteeing, swearing to do), and several theorists have no further use for it (e.g. Searle 1969: chapter 3; Leech 1983). In a way, this is unsurprising as (i) one of the core meanings of commitment is "promise", (ii) promises are the core type of commissive speech acts, and (iii) early speech-act theorists tend to use the term in a non-technical sense. Note in this respect that dictionaries or encyclopaedias that have an entry for commissive usually define the notion in terms of commitment. Thus, Bussmann (1996: 83): commissive = "Speech act meant to commit a speaker to some course of action, [...]" (a similar definition occurs in Crystal 1997: 71). In these sorts of uses, the locutions to commit NP to or to make a commitment to are barely more than synonyms of to undertake an obligation or to assume responsibility for.

However, some early students of speech acts made use of the notion in their accounts of other acts too. Thus, Toulmin (1958) uses the verb to commit NP (to) in his characterisation not only of promises but also of predictions (1958: 50ff) and, more generally, statements (1958: 76). Interestingly, Toulmin applies it to different 'targets': in most cases promises commit the speaker tout court (in all but one instance, the object of the commitment is left implicit), whereas statements about the future commit the speaker to - it seems - the very content (or consequences) of the act itself. Alternative formulations have the speaker committing herself by performing a certain speech act.

One finds a similarly extended use of the verb to commit NP to in Austin's lectures. Thus, assertions/statements (1975: 51-52, 139) and performatives (ibid.: 89) also commit their utterer to performing other acts. In Searle's early work on speech acts, the term only comes up in connection with commissives, but in Expression and Meaning it is used in definitions of the illocutionary point (the core component) of both commissives and assertives. The point of an assertive is "to commit the speaker (in varying degrees) to something's being the case, to the truth of the expressed proposition" (1979: 12). A similar use can be observed in Vanderveken (1990: 172, 182, 183). Some authors (Lyons 1977: 734; Green 2007) assume that the performance of a speech act of any sort commits the speaker to certain beliefs and/or intentions (those stated in the 'sincerity conditions' of each illocutionary act). [In this volume, Deschamps makes extensive reference to Lyons's account of speech acts; Gunlogson and Poschmann suggest ways of making sense of speaker commitment in questions; Kissine discusses commitment in assertions; Morency, Oswald \& Saussure assess speech-act-theoretic views on commitment.]

But there is another sense of commitment in speech-act theory, a technical one, which was introduced in Searle and Vanderveken (1985):

A theory of illocutionary logic of the sort we are describing is essentially a theory of illocutionary commitment as determined by illocutionary force. The single most important question it must answer is this: Given that a speaker in a certain context of utterance performs a successful illocutionary act of a certain 
form, what other illocutions does the performance of that act commit him to?" (1985: 6)

What is at stake is a different notion of commitment from the non-technical one identified so far. Searle \& Vanderveken understand illocutionary commitment as a logical, semantic relation between illocutionary acts. The idea is that "sometimes by performing one illocutionary act a speaker can be committed to another illocution" (1985: 23), and this commitment is not a matter of the speaker's preferences or mental states. Searle \& Vanderveken further indicate that illocutionary commitment can be 'strong' or 'weak'. This not being the place to provide formal definitions, we will be content with a few illustrations. All other things being equal, the speaker who says $I$ beg you to do $A$ is strongly committed to I ask you to do A, because every act of begging is an act of asking. And the person who utters the directive Open the door is strongly committed to the assertive The door is closed, because the latter is a presupposition of the directive. Speech act $S_{1}$ strongly illocutionarily commits the speaker to $S_{2}$ if in performing $S_{1}$ she automatically also performs $S_{2}$. As for weak illocutionary commitment, it concerns cases where the performance of $S_{1}$ also satisfies the conditions on the performance of $\mathrm{S}_{2}$, even though $\mathrm{S}_{2}$ is not performed in the performance of $\mathrm{S}_{1}$. Thus a speaker who asserts Socrates is a man and All men are mortal is weakly illocutionarily committed to the assertion that Socrates is mortal. Much of Searle \& Vanderveken (1985) and of Vanderveken (1990, 1991) is devoted to commitment so understood.

The previous discussion points to an additional feature of commitment in studies of speech acts that deserves our attention, gradability. It can be understood in different ways. Thus, Toulmin (1958: chapter 2) offers a detailed discussion of means of qualifying commitment by using modal expressions like probably (this shows there are ties between studies of speech acts and modality, see next section). So, commitment may be unreserved, but it may also be 'guarded'. A different, though related, way of approaching the gradability of commitment is via the meaning of illocutionary verbs. Vanderveken's (1990: 172) definitions of both suggest and guess involve a reference to a reduced commitment to the truth of a proposition. In a similar vein, Green (2007) writes that "conjecturing lays you bare to less demanding challenges than asserting". These last two authors are actually referring to the way Searle \& Vanderveken (1985) defined illocutionary forces: each force is defined in terms of the values of seven components. Two of these are framed in terms of strength: strength of the 'illocutionary point' (e.g. a command is stronger than a request), and strength of the 'sincerity condition' (e.g. "a speaker who supplicates expresses a stronger desire than a speaker who requests" (1985: 191)). Katriel \& Dascal (1989) have criticised this position for confusing commitment with involvement. Commitment is absolute, all-or-nothing; involvement is graded. Therefore, they claim, what is at stake in the two 'strength-components' of the definition of illocutionary forces is involvement, not commitment. [Contributions that take a 
stand on the gradability of commitment are Cornillie \& Delbecque; Izutsu; Lansari. Contributions that appeal to a comparable, though not identical, notion of involvement are Cornillie \& Delbecque; De Saeger]

In this section, we have seen that, apart from its use in Searle \& Vanderveken's illocutionary logic, commitment is not a technical term. In its non-technical uses, the basic pattern is this: the performance of an illocutionary act commits the speaker to further acts. However, we have also seen that an assertion commits the speaker to the truth of the proposition expressed. One final observation: most scholars explicitly or implicitly take commitment to be a public attitude. Commitment publicly results from the performance of a speech act. This is especially clear in Green (2007) who takes the performance of a speech act to consist in the "overt manifestation of a commitment".

\subsection{Modality}

In studies of modal expressions, the term commitment is often part and parcel of the definition of epistemic modality. For instance, Palmer puts forward the suggestion that

the term 'epistemic' should apply not simply to modal systems that basically involve the notions of possibility and necessity, but to any modal system that indicates the degree of commitment by the speaker to what he says. (1986:51)

For similar characterisations, see e.g. Lyons (1977: 797), Bybee (1985: 166f); de Haan (1999), Huddleston \& Pullum (2002: 52), and many others. Interestingly, Palmer means to include evidential markers within epistemic expressions, but this line is resisted by e.g. de Haan and Aikhenvald, who assume evidential markers to be neutral with respect to any epistemic commitment to the truth of the proposition expressed. In Aikhenvald's conception, evidentiality is a "category in its own right" (2004: 7), designating a source of information (2004: 4). A linguistic expression is considered an "evidential proper" only if its core meaning is evidential (2004: 105). If its core meaning is something else (e.g. mood, modality, reported speech, etc.), but the marking of the information source also somehow comes in, Aikhenvald speaks of an "evidentiality strategy" or "evidential extension of a non-evidential category" (ibid.). ${ }^{2}$ On the other hand, a genuine evidential marker can have nonevidential secondary meanings, like epistemic modality (2004: 6) or "commitment to the truth of the statement" (2004: 192), but the author stresses that this is not necessarily the case, even for markers of visual evidence: "the truth value of an utterance is not affected by an evidential" (2004: 4).

Working within a truth-conditional framework, Papafragou (2006) argues against the view that epistemically used modals indicate the degree of speaker commitment to the propositional content. This she does inasmuch as this view goes hand in hand with the widely held assumption that epistemic modals make 
no contribution of the truth-conditions of the utterances in which they occur (in other words, they are not part of the propositional content). Not only does she reject the general claim that epistemic modals do not contribute to truthconditions, but she also adduces evidence against the weaker claim that subjective epistemic modals do not contribute to truth-conditions.

This last point alludes to the distinction between objective and subjective epistemic modality made by Lyons (1977: 797). Whereas the former modality concerns straightforward presentations of possibilities or necessities as matters of fact, the latter serves to qualify speaker commitment to the truth of her utterance (see also 1995: 331). Thus, in Lyons's view, only objective, not subjective, epistemic modality is part of the proposition expressed. However, contends Papafragou, there is empirical evidence that even subjective epistemics play a propositional role. The question then is how to account for the strong intuition that subjective epistemics express the speaker's degree of commitment to the proposition expressed (and therefore somehow appear to stand outside it). Papafragou claims that subjective epistemics are indexical: their semantics includes a parameter for the epistemic community on which the modal judgment is based. In extreme cases - Lyons's subjective uses - this community is reduced to the speaker at the moment of utterance. This way, the indication of speaker commitment is now "taken to be an intuition not about truth conditions but about the type of epistemic agent providing the background assumptions for epistemic modality" (2006: 1700).

Nuyts's notion of 'performativity' is precisely designed to capture such a view of speaker commitment. Nuyts distinguishes between 'performative' and 'descriptive' (uses of) modal expressions:

A performative expression marks an attitude [an evaluation of a proposition] to which the speaker is fully committed at the moment of speech. In a descriptive use, the speaker is not committed, but is only reporting on an attitude regarding some state of affairs held by someone else, or by the speaker at some point in time other than the moment of speech, or as a hypothetical possibility. (2006:

15)

This distinction comes into its own in descriptions of epistemic modals. Nuyts suggests that epistemic verbs and adjectives can be used either way, but that epistemic adverbs and auxiliaries can only be used performatively, i.e. to express the speaker's commitment. Interestingly too, the distinction can be applied to deontic modal expressions, but not to dynamic modality, all instances of which are descriptive, according to Nuyts. [n the previous discussion, commitment is a matter of who makes an evaluation, the speaker or someone else (i.e. who is its source). The contributions that deal with the notion of source are Celle; Cornillie \& Delbecque; Deschamps; Gunlogson; Lansari, who speaks of 'origin'] 
Faller (2006) appeals to Nuyts's performativity (renamed 'mperformativity', with $m$ for mental) to show that certain tests designed to determine whether a given expression in a sentence affects truth-conditions in fact capture something totally different: whether the expression is used performatively or descriptively. Compare these examples:

(1) ?If Max may be lonely, his wife will be worried. (from Papafragou 2006: 1690)

(2) If the gardener might be the thief, then we should watch her carefully.

The near-unacceptability of examples like (1) has been taken to show that may is not truth-conditionally relevant, because all truth-conditional elements of a sentence should be embeddable under if. But might in (2) is embeddable, so what is the difference? Faller's answer is that may in (1) is used performatively whereas might in (2) is descriptive. The intuition is that the speaker "may in fact be completely certain that the gardener is not the thief" (Faller 2006) and yet utter (2). This analysis is very close to Papafragou's (2006: 1696). If correct, it shows that certain aspects of interpretation which were previously understood in terms of relevance/irrelevance to truth-conditions are in fact a matter of whether the speaker is committed to a modal judgment or not.

There are other interesting connections between modality and commitment. We will only mention one more: as in studies of speech acts, commitment is widely understood by students of modality as a gradable notion. Different expressions mark different degrees of commitment, and several authors therefore speak of 'weak' and 'strong' commitment (in a sense closer to Toulmin's 'guarded vs. unreserved' than to Searle \& Vanderveken's 'weak vs. strong'). Weak commitment would be expressed by may, perhaps, possible, etc.; strong commitment by must, certainly, necessary, etc. [Contributions that study modal markers of commitment are Celle; Cornillie \& Delbecque; Pietrandrea]

The notion that emerges from the study of modality does not overlap perfectly with the notion that emerges from speech-act theory. It is notable that the modal notion is seldom expressed by means of the verbal locution to commit $N P$ to in the active voice. Rather than an action (and/or its result), commitment here is essentially a speaker's attitude towards the truth of some propositional content. In this respect, it is close to the commitment that speech-act theorists associate with assertions. It is not surprising, therefore, that Lyons (1995: 254) should call the illocutionary commitment typical of assertions 'epistemic'. Lyons actually pushes the analogy further. The sort of illocutionary commitment associated with directive acts he calls 'deontic', thus underlining the connections between the modal and the speech-act notions. 


\title{
1.3 Formal models of dialogue/argumentation.
}

Hamblin (1970) is the seminal publication that firmly established the concept of commitment in research concerned with the formal modelling of dialogue and argumentation. In his investigation of logical fallacies, Hamblin, an argumentation theorist and informal logician, pursues the goal of modelling the dynamics of dialogue:

\begin{abstract}
A speaker who is obliged to maintain consistency needs to keep a store of statements representing his previous commitments, and require of each new statement he makes that it may be added without inconsistency to this store. The store represents a kind of persona of beliefs: it need not correspond with his real beliefs, but it will operate, in general, approximately as if it did. We shall find that we need to make frequent reference to the existence, or possibility, of stores of this kind. We shall call them commitment-stores: they keep a running tally of a person's commitments. (1970: 257)
\end{abstract}

First, note that Hamblin uses commitment as a count noun. A commitment is not an attitude or an action, but "a statement-token", in Hamblin's original formulation. Later developments of Hamblin's work have tended to view commitments as propositions (i.e. contents of statement-tokens). Each participant in a conversation has her own commitment-store, which acts like a constraint on further conversational moves. Thus, a speaker is not licensed to produce statements that are inconsistent with one or more of her commitments. Once again, we are close to the commitment that speech-act theorists associate with assertions. Note in passing that, even though such commitment is to the truth of an asserted proposition, it is at the same time a commitment to a future course of action (as with promises). That is because showing one's adherence to a proposition has concrete consequences: one may have to provide justifications of a claim if challenged, and one is bound to avoid making contradictory claims. [Kissine's contribution provides a detailed discussion of commitment to truth vs. commitment to having justifications.]

Several issues have been addressed by scholars who have adopted the basics of Hamblin's framework. The first is clearly linked to Searle \& Vanderveken's logical relation of illocutionary commitment: the question is what exactly a speaker who makes an assertion is committed to: only the asserted content? different types of implications of that asserted content (presuppositions, implicatures)? [Morency, Oswald \& Saussure's contribution considers the issue at length; Gunlogson and Izutsu endorse commitment to an implicit content.] Another question is whether commitment-stores should include only propositions, or other types of commitments. Hamblin himself was aware that modelling of certain forms of dialogue would require including 'imperative' and 'emotive' commitments too. Recently, drawing on Ginzburg \& Sag's (2000) ontology of contents (see also Leech 1983: 114-118) and following up on a suggestion made 
by Gazdar (1981), Beyssade \& Marandin (2006, forthcoming) have proposed a general account of speech acts in dialogue in which commitment can bear on a variety of objects. Thus, a directive speech act can be said to commit the speaker to an 'outcome', a question to a 'propositional abstract' and an exclamation to a 'fact'. A related question is whether certain speech acts are capable of affecting another participant's commitment-store. Gunlogson (2001) argued that rising declarative sentences update the addressee's commitment-store, not the speaker's. Reluctant to accept the idea of publicly committing another agent, Beyssade \& Marandin (2006) prefer to speak of a 'call on addressee'. In their framework, every speech act has two main impacts: it updates the speaker's commitment and calls on the addressee to take some action. In her contribution to this volume, Gunlogson has modified her previous theory in such a way that a speaker uttering a rising declarative sentence now does make a commitment, but this commitment is 'contingent' upon the addressee's endorsement of the proposition expressed. [See also Poschmann for a lively debate with Gunlogson.]

The public character of commitment in dynamic models of dialogue is a requisite ingredient. Formal semanticists and argumentation theorists are keen to insist that a commitment is not a mental state (though there will be relations with mental states):

a commitment is not necessarily a belief of the participant who has it. We do not believe everything we say; but our saying it commits us whether we believe it or not. The purpose of postulating a commitment-store is not psychological. (Hamblin 1970: 264)

Similar claims can be found in Gunlogson (2001; she often resorts to the odd collocation 'public beliefs'), or in Beyssade \& Marandin (forthcoming). There is an obvious parallel with this statement by Lyons:

\begin{abstract}
Anyone who states a certain proposition is committed to it, not in the sense that they must in fact know it or believe it to be true, but in the sense that their subsequent statements - and anything that can be legitimately inferred from their accompanying and subsequent behaviour - must be consistent with the belief that it is true. (1995: 254)
\end{abstract}

The view here is that (a) commitment is not a mental state; it is the expression (sincere or not) of a mental state. Yet, perhaps this view requires some qualification. The famed argumentation theorist Douglas Walton suggests that, at least for the sake of modelling everyday argumentation, commitment-stores ought to be divided into "two subsets - a light side of overt, expressed, explicit commitments, and a dark side of commitments that are only partially apparent or plausibly surmised by one or more of the participants in the dialogue" (1993: 97; also 1995: 102f). 
It is clear from this section that dialogue and argumentation theorists make extensive use of speech-act-theoretical concepts. This convergence of interests did not escape the Levinson of Pragmatics, who argued for a so-called 'contextchange theory of speech acts' (1983: 276-277). Recently, however, Green (2007) still reflects that there is, curiously, little interaction between speech-act theory and dialogue-modelling. Yet both bodies of research largely draw on the same notions, and it is apparent from what we have just seen that there are marked similarities between the speech-act-theoretic and the formal semantic understanding of commitment.

\section{Our own commitment corpus}

In the eleven papers in this volume, more than $83 \%$ of occurrences of the commit- cognates are tokens of the noun commitment. A little less than $8 \%$ are occurrences of the structure speaker commits (herself) to. Less than $7,5 \%$ are occurrences of speaker is committed to. And 1,5\% are occurrences of something commits speaker to.

Interestingly, the only authors who use the latter construction (Deschamps, Gunlogson, Kissine, Poschmann) are those who are closest to the speech-acttheoretic approach and/or the dialogue-modelling approach. This is not surprising. Use of the construction with an inanimate subject (e.g. assertion, declarative sentence, illocutionary force, discourse move) seems to correspond with the least psychologising conception of commitment, precisely that which is upheld by dialogue and argumentation theorists and - slightly less forcefully by students of speech acts. When the referent of the subject of to commit NP to is inanimate, commitment is presented as a 'contractual', conventional consequence of performing a speech act, something independent of the speaker's actual state of mind. This is especially striking in the few cases where the NP stands not for the speaker but for the addressee (cf. Poschmann's treatment of echo-questions in terms of 'commitment-shift'). In contrast, it could be argued that the construction speaker commits (herself) to, which is comparatively more frequent, denotes a more psychological understanding, because the speaker is represented as deliberately undertaking commitment.

There is certainly some truth to this, but the contrast must not be overstated. The two notions are not necessarily incompatible. For instance, one may have a contractual view of illocutionary commitment and a psychological understanding of the modal qualification of commitment. But even illocutionary commitment alone can be grasped either 'contractually' or psychologically. In some cases, it is difficult to decide which understanding prevails. Take this sentence from Gunlogson's paper: "In uttering [You got a haircut, with either rising or falling intonation], Max commits himself, as a source, to the proposition that Laura got a haircut". We have a speaker who - it can be assumed - deliberately commits himself. At the same time the mention of in 
uttering [that sentence] is conducive to a contractual reading: "the utterance of that sentence commits Max ...".

Some of the verbs or adjectives collocating with the noun commitment may also shed light on psychologising vs. non-psychologising conceptions. When "weak commitment" is equated with distancing (cf. brief discussion in Cornillie \& Delbecque), the notion is psychological, unless one assumes that certain markers effect distancing, that they distance the speaker from her utterance (therefore turning distance into a public rather than a private attitude). In a similar vein, Morency, Oswald \& Saussure's idea that "attributing/misattributing commitment" is part of the interpretation of the speaker's communicative intentions makes commitment a psychological notion. And when commitment is "avoided" or "deferred" (Celle), or "withdrawn" (Izutsu), when it is "confident" (Pietrandrea), or when the speaker commits herself "in anticipation or in retrospect" (Celle), it is again likely that we are dealing with a psychological state. By contrast, when Kissine writes that "by performing an assertion, S contracts a public commitment", we are dealing, quite literally, with the contractual notion.

We have already mentioned that commitment can occur as a count or noncount noun. This has some bearing on how commitment is viewed. The noncount noun is used by most contributors. The few who also make extensive use of the count noun (Gunlogson, Poschmann - "the proposition is a commitment") are the dialogue theorists with a public, non-psychological concept of commitment. Still, the collocation a commitment can also designate the speaker's mental state about a particular proposition (cf. Lansari, Morency, Oswald \& Saussure), or a particular type of commitment (cf. Kissine, Pietrandrea)

The last point we wish to bring up in this section is the use of the construction speaker is committed to. This can be understood as indicating (a) commitment resulting from an action of committing oneself (or an event of a dialogue move committing a speaker). However, there are cases where the expression refers to a prior commitment. Thus, Cornillie \& Delbecque talk of markers or constructions indicating a commitment or lack of commitment; and Izutsu writes that it is "awkward for a speaker who is only weakly committed to an assumption to give a command to act according to the assumption". Such uses only make sense if the speaker is already committed before producing her utterance. There are also cases where the expression seems to refer both to a prior and a resulting commitment. Thus, when Deschamps says of a speaker who has performed a directive act that she is committed to a desire, she states both a prior, private 'sincerity condition' of the act, and its public consequence. This shows that there is no fundamental incompatibility between the two readings. 


\section{The contributions}

Agnès CELLE describes the modal uses of the future tense and the conditional in French in terms, respectively, of speaker commitment and speaker noncommitment, and contrasts the use of the two markers with that of their English counterparts will, allegedly, etc. Commitment is viewed by the author as "part and parcel of assertion": in the normal case the speaker is the source of the propositional content of her utterance and commits herself to its truth. When the speaker is not so committed, assertion is suspended.

Bert CORNILliE \& Nicole DelBeCQue propose a description of two Spanishlanguage phenomena - deviant que / de que constructions and the modal verbs poder, deber and tener que - in terms not of weak vs. strong commitment (corresponding to weak vs. strong certainty), as is traditionally done, but of high vs. low speaker involvement. The latter concept pertains to the role of the speaker as a conceptualizer in the construal of the meaning of a linguistic expression. In doing so, they replace the notion of commitment, widely used for the description of those markers, by that of involvement.

In his empirical study of Spanish que-clauses after a cognition verb (e.g. creer, pensar, opinar), Bram DE SAEGER explains why the notion of involvement proves more useful than that of commitment. Cognition predicates being non-factive, the speaker is not committed to the truth of the content of the complement clause. The author distinguishes various patterns of involvement as a function of two pairs of opposite parameters: speaker vs. subject perspective on the content of the clause, and argumentative vs. descriptive use of that content.

Karen DESCHAMPS considers commitment both in terms of a psychological state of the speaker (an attitude towards a propositional content) and the speaker's responsibility (his being the source of a content). She uses the notion to account for the differences between the normative use and the reportive use (or directive + declarative force vs. assertive illocutionary force) of deontic sentences in four different types of legal-administrative texts in Dutch. It turns out that the two ways of understanding commitment (in terms of psychological states vs. responsibility) do not overlap perfectly.

Christine GuNLOGSON gives a formal semantic and pragmatic account of declarative questions in English. She starts from the principle that declaratives always express speaker commitment - even when used as questions. Each commitment pragmatically requires a source ('Source Principle') and being a source involves having adequate evidence for a proposition. Furthermore, speaker commitment can only be reconciled with questionhood if it is contingent. The author shows that the requirements that a source have adequate evidence and that commitment be contingent explain the distributional restrictions on 'initiating declarative questions'. 
Mistuko Narita IZUTSU argues that commitment can throw light on the dissimilarities between two Japanese markers of concession, -noni and -kedo. Though some contexts allow the use of both connectives (which then translate roughly as 'although'), many contexts disfavour one of the two. The author argues that such distributional differences stem from the fact that -noni expresses strong commitment and -kedo weak commitment to an implicit assumption underlying the concessive meaning. A similar analysis is given for the Russian connectives $a$ and $n o$.

Mikhail KISSINE examines two ways of defining assertion in terms of commitment: commitment to the truth of the proposition and commitment to having evidence or justifications for the propositional content. He argues that the latter commitment - which on Brandom and Williamson's dominant accounts must be understood as commitment to having demonstrative justifications - is too strong a condition on assertion. By contrast, commitment to the truth of the proposition is shown to apply even in the case of modally weakened assertions.

In her empirical paper, Laure LANSARI describes the contrasts between be going to and aller + infinitive as used in if-constructions, in narratives and in news texts. She shows that in these contexts the notion of commitment throws light on significant differences between the two markers: aller + inf. expresses a variety of values, notably 'ambivalent commitment', whereas be going to usually signals that the origin of commitment is separate from the speaker.

Patrick Morency, Steve OSWALD \& Louis de SAUSSURE examine how a hearer attributes commitment to a speaker. The authors' key concern are the beliefs a hearer forms about what he infers the speaker has committed to in making her utterance. Working within a relevance-theoretic framework, they regard strategies of inferring commitment as part of a general process of inferring speaker meaning (explicit and implicit).

Paola PIETRANDREA examines the semantic and distributional differences between two Italian markers of strong commitment, certamente and sicuramente, and traces them to a difference in terms of commitment. Certamente is analysed as a marker that attributes the point of view expressed in the sentence to another discursive voice and "marks a commitment to the truth of a content that is expressed in agreement or in opposition to other discursive voices". Sicuramente is analysed as a marker of alternative monophonic judgments; it marks "the progression of commitment or its restriction to a limited domain of application".

Claudia POSCHMANN studies declarative questions in terms of commitment. She distinguishes between echo-questions and confirmative questions (rising ones and falling ones), notably on the basis of their different linguistic behaviour. Confirmative questions involve speaker-commitment (dependent or not on the addressee's acknowledgment). Echo-questions do not; they involve a 
commitment-shift to some other agent in the context (e.g. the one who is echoed) and leave the speaker's set of commitments untouched.

phdebrab@yahoo.co.uk,patrick.dendale@ua.ac.be

\begin{abstract}
Notes
${ }^{1}$ In what follows, we will often use the shortcut the term to refer to commitment and its verbal and adjectival cognates.

${ }^{2}$ An example is supplied by the French conditional. This marker, described by some linguists as a marker of non-commitment ('non prise en charge' in Abouda 2001) or as a 'mixed grammatical marker' of 'zero modalisation' (read 'non commitment') plus evidentiality ('or mediation', in Kronning's 2005 terminology), can be used in a particular context for information "obtained from a questionable secondhand source for whose veracity the speaker refuses to take responsibility" (2004: 105). This is typically an evidentiality strategy in Aikhenvald's sense.
\end{abstract}

\title{
References
}

Abouda, L. 2001. "Les emplois journalistique, polémique, et atténuatif du conditionnel. Un traitement unitaire". In P. Dendale \& L. Tasmowski (eds), Le conditionnel en français. Metz: Université de Metz, 277-294.

Aikhenvald, A. 2004. Evidentiality. Oxford: OUP.

Austin, J.L. 1975. How to Do Things with Words. Oxford/New York: OUP.

Beyssade, C. \& Marandin, J.-M. 2006b. "The speech act assignment problem revisited: Disentangling speaker's commitment from speaker's call on addressee". In O. Bonami \& P. Cabredo-Hofherr (eds), CSSP's Proceedings. (http://www.cssp.cnrs.fr/)

Beyssade, C. \& Marandin, J.-M. forthcoming. "Commitment: attitude propositionnelle ou attitude dialogique?". In D. Coltier, P. Dendale \& P. De Brabanter (eds), La notion de prise en charge en linguistique. Paris: Larousse. (Langue française)

Bussmann, H. (ed) 1996. Routledge Dictionary of Language and Linguistics, transl. from the German and edited by G. Trauth \& K. Kazzazi, London/New York: Routledge.

Bybee, J. 1985. Morphology: A study of the relation between meaning and form. Amsterdam: Benjamins.

Crystal, D. 1997 (4 ${ }^{\text {th }}$ edition). A Dictionary of Linguistics and Phonetics. Oxford, UK/Cambridge, Mass.: Blackwell.

de Haan, F. 1999. "Evidentiality and epistemic modality: setting boundaries". Southwest Journal of Linguistics 18: 83-101 (http://www.u.arizona.edu/ fdehaan/ papers/SWJL99.pdf)

Faller, M. 2006. "Evidentiality and epistemic modality at the semantics/pragmatics interface". Ms. (http://www.eecs.umich.edu/ rthomaso/lpw06/fallerpaper.pdf)

Gazdar, G. 1981. "Speech act assignment". In A.K. Joshi, B.L. Webber \& I.A. Sag (eds), Elements of Discourse Understanding. Cambridge: CUP, 64-83. 
Ginzburg, J. \& Sag, I.A. 2000. Interrogative Investigations: The form, meaning, and use of English interrogatives. Stanford, CA: CSLI.

Green, M. 2007. "Speech acts". Stanford Encyclopedia of Philosophy. (http://plato.stanford.edu/entries/speech-acts)

Gunlogson, C. 2001. True to Form. Rising and Falling Declaratives as Questions in English. PhD dissertation, University of California, Santa Cruz. Published in 2003. London/New York: Routledge.

Hamblin, C.L. 1970. Fallacies. London: Methuen.

Huddleston, R. \& Pullum, G.K. 2002. The Cambridge Grammar of the English Language. Cambridge: CUP.

Katriel, T. \& Dascal, M. 1989. "Speaker's commitment and involvement in discourse". In Y. Tobin (ed), From Sign to Text. Amsterdam: Benjamins. (Foundations of Semiotics, 20)

Kronning, H. 2005. "Polyphonie, médiation et modalisation: le cas du conditionnel épistémique". In J. Bres et al. (eds), Dialogisme et polyphonie. Approches linguistiques. Bruxelles: De Boeck/Duculot, 297-323.

Leech, G. 1983. Principles of Pragmatics. London/New York: Longman.

Levinson, S.C. 1983. Pragmatics. Cambridge: CUP.

Lyons, J. 1977. Semantics, 2 vol. London/New York: CUP.

Lyons, J. 1995. Linguistic Semantics. Cambridge: CUP.

Nuyts, J. 2006. "Modality: overview and linguistic issues". In W. Frawley (ed), The Expression of Modality. Berlin/New York: Mouton de Gruyter, 1-26.

Palmer, F.R. 1986. Mood and Modality. Cambridge: CUP.

Papafragou, A. 2006. "Epistemic modality and truth conditions". Lingua 116: 16881702.

Searle, J. 1969. Speech Acts. An essay in the philosophy of language. Cambridge: CUP.

Searle, J. 1979. Expression and Meaning. Studies in the theory of speech acts. Cambridge: CUP.

Searle, J. \& Vanderveken, D. 1985. Foundations of Illocutionary Logic. Cambridge: CUP.

Vanderveken, D. 1990. Meaning and Speech Acts, vol. 1. Principles of language use. Cambridge: CUP.

Vanderveken, D. 1991. Meaning and Speech Acts, vol. 2. Formal semantics of success and satisfaction. Cambridge: CUP.

Walton, D. 1993. "Commitment, types of dialogue, and fallacies". Informal Logic 14: 93-103.

Walton, D. 1995. A Pragmatic Theory of Fallacy. Tuscaloosa/London: University of Alabama Press. 